\title{
Herbezinning op het fiscale regime voor inkomsten uit aandelen
}

Prof. Dr. L.G.M. Stevens

De binnen de economische theorie gew'enste fiscaal neutrale behandeling van kapitaalstromen wordt door het Nederlandse belastingheffingstelsel verstoord zonder dat daarvoor overnigende argumenten kumnen worden aangediagen. Zo worden eigen-vermogensierschaffers fiscaal gediscrimineerd ten opzichte van de reemd-vermogensverschaffers. Maar ook binnen de kring ran de eigen-vermogensverschaffers treden onder invloed van de in de fiscale rechtspraktijk bemutbare taxplanningsmogelijkheden belangrijke verstoringen op. Zo bepaalt de keuze van de rechtsvorm of de ondernemingswinst w'ordt belast naar het progressieve tarief ran de inkomstenbelasting (0 tot 60\%) dan wel naar het proportionele tarief van de vennootschapsbelasting $35 \%$ met een tariefdrempel van $40 \%$ over de winst tot $f 100.000,-)$. Ook blijkt de juridische vormgeving van de winstuitdeling een hepalende factor voor de lastendruk op het ter beschikking gestelde risicodragende vermogen. Naast de reeds op vennootschapniveau geheven winstbelasting wordt de particuliere aandeelhouder immers geconfionteerd met de heffing van inkomstenhelasting. Afhankelijk van de juridische vormgeving is op deze winstuitdeling het progressieve tarief van toepassing dan w'el een proportioneel tarief van $45 \%, 20 \%$ of $10 \%$. In sommige gevallen kan zelfs worden bereikt dat de gerealiseerde winstreserve geheel onbelast blijft.

De door de diversiteit van tarieven uitgelokte transformatieprocessen leiden niet alleen tot onnodig ingewikkelde fiscale wetgeving, maar

Prof. Dr. L.G.M. Stevens is verbonden aan het Fiscaal Economisch Instituut van de Erasmus Universiteit Rotterdam. verstoren bovendien de optimale allocatie van kapitaal. Voorts ontstaat binnen het fiscale stelsel vanwege de belastingarbitragemogelijkheden toenemende spanning tussen de geldende fiscale regimes voor kapitaal en arbeid. Enerzijds is de hoge kapitaalmobiliteit een helangrijke rem op de mogelijkheden van een staat eenzijdig een hoge belastingdruk op kapitaal(inkomsten) te handhaven, maar anderzijds vereist het aan de draagkrachtgedachte ten grondslag liggende gelijkheidsheginsel dat arheidsinkomsten en kapitaalinkomsten gelijkelijk worden belast.

\section{Gebrekkig fiscaal winstbegrip}

Een in het oog springende tekortkoming van ons helastingstelsel is het gebrekkige karakter van het geldende inkomenshegrip. Na meer dan honderd jaar blijft het op dit punt nog steeds tobben geblazen. Het meest in overeenstemming met het principe van een draagkrachtheffing is een inkomenshegrip gehaseerd op de vermogensvergelijkingstheorie. Binnen deze theorie worden alle vermogensvermeerderingen en -verminderingen tot het inkomen gerekend, ongeacht hun herkomst. In Nederland wordt een dergelijk breed inkomenshegrip evenwel niet toegepast, zelfs niet in afgezwakte vorm door toepassing van een vermogensuinstbelasting. De uitvoeringstechnische complicaties bleken tot op heden daarvoor een beslissend obstakel.

Met name bij de inkomsten wit vermogen wordt op grond van het geldende bronnenstelsel een scherp onderscheid gemaakt tussen de belaste inkomstensfeer en de onhelaste vermogensffeer. Voor zover de belastinghetaler het in 
zijn macht heeft het afsplitsen van progressief belaste inkomsten te voorkomen, in ruil voor onbelaste waardestijging van de bron, zal hij dit nastreven. Vele beleggingsvormen zijn op deze beleggersvoorkeur afgestemd. Er is dan ook een keur van beleggingsprodukten ontwikkeld waarin wordt gepoogd de belaste interestophrengst te transformeren in onhelaste vermogensgroei. Zo heeft momenteel bijna elke financiële instelling haar eigen rentegroeifonds waarin belaste renteopbrengsten worden getransformeerd in onhelaste koerswaardestijging van aandelen.

Het uit het bromnenstelsel voortiloeiende gebrekkige inkomenshegrip en de in de uitroeringspraktijk daarmee samenhangende problemen zijn in feite alleen maar via wetgevende maatregelen te repareren. De oplossingsrichtingen zijn tweeërlei. De eerste oplossingsrichting is de introductie van forfaitaire-rendementshepalingen die - weliswar gebrekkig in hun vormgeving - een alternatief vormen voor de vermogensaanwashelasting. De tweede oplossingsrichting is de subjectivering van de objectievebronstructuur, waarmee een soort partiële vermogenswinstbelasting wordt ingevoerd.

Mijn herzieningsvoorstel is gericht op de inkomsten uit aandelen. De buiten deze sfeer spelende tekortkomingen van het fiscale inkomensbegrip blijven daarmee w'elisw'aar onopgelost, maar soms is her beste de rijand van het haalbare. Ik heb er daarom voor gekozen althans voor de inkomsten uit aandelen te komen tot een meer evenwichtig stelsel. Resultaten op dat terrein kunnen vervolgens een verdergaande sanering van het fiscale stelsel stimuleren.

\section{Belastingbesparende aandelenconstructies}

Het bronnenstelsel en het daaruit vortvloeiende gebrekkige fiscale inkomensbegrip heeft ook zijn sporen nagelaten in het geldende fiscale regime voor de inkomsten uit aandelen. Kort gezegd behoort thans alles wat een aandeelhouder van de aandelenvennootschap terugontvangt hoven hetgeen er als kapitaal is ingebracht tot de belaste inkomsten. In het fiscale jargon staat dit principe bekend als de 'genviddeldekapitaalregel'. In de huidige wetssystematiek w'ordt dit begrip op objectieve wijze ingeruld. Dat wil zeggen dat het kapitaalbegrip wordt bezien vanuit de collectiviteit ran aandeelhouders. Wat de individuele aandeelhouder heeft gestort en terugontvangen is daarbij niet van belang. Zo blijft de liquidatie-uitkering ad 300\% van een $B V$, die destijds gelijke nominale bedragen aan aandelen uitgaf tegen respectievelijk $100 \%$ en bij latere emissie tegen $500 \%$, voor alle aandeelhouders belastingrrij, hoewel de oude aandeelhouders $200 \%$ meer terugkrijgen dan zij stortten, en de nieuwe aandeelhouders een gelijk bedrag als niet-aftrekbaar vermogensverlies moeten incasseren. Dit betekent ook dat helastingwije agiobonussen kunnen worden uitgegeven ten koste van de nieuw'e aandeelhouders die het agio inbrachten.

Op basis van deze collectieve benadering zijn diverse belastinghesparende constructies bedacht. Ze worden onder benamingen als 'oppomp-constructie', 'agio-constructie' of 'turboconstructie' aan de man gebracht. Kerndoelstelling van al deze constructies is te bereiken dat via inbreng van nieuw kapitaal belastingrrije vermogensoverheveling kan plaatsvinden naar oude aandeelhouders/natuurlijke personen die onder het genoemde collectieve regime vallen. Dit geschiedt door nieuw'e aandeelhouders/ rechtspersonen te interesseren voor een emissie, waarbij een groot bedrag aan agio moet worden ingebracht. Deze aandeelhouders/rechtspersonen zullen meestal op grond van de deelnemingsvrijstelling dan wel op grond van het geldende fiscale (subjectieve) winsthegrip over de winstuitdelingen geen belasting hoeven te betalen. Deze tweeslachtigheid in het systeem vormt de oorsprong van de belastingbesparende constructies. De oude aandeelhouders krijgen door het ophogen van het kapitaal een voordeel; de nieuw'e hebben geen nadeel. De schatkist, dus de gehele gemeenschap, is echter het kind van de rekening.

Slechts door invoering ran cen gestortkapitaaltoets per individuele aandeelhouder of door de invoring van een vermogenswinsthelasting zou een theoretisch afdoende oplossing kunnen worden bereikt. De uitvoeringstechnische problemen en een onvoldoende maatschappelijk draagvlak blokkeren echter deze oplossingstichting. Daarom heb ik binnen de aandelensfeer gekozen voor cen meer beperkte en vereenvoudigende reparatie. Ze voorziet in een subjectivering van het aanmerkelijk-belangregime. 


\section{Herzieningsvoorstel}

Kern van mijn herzieningsvoorstel is de invering ran één vast tarief voor alle inkomsten uit aundelen van 20\% e'n een gelijk tarief roor winst uit anmerkelijk belang. De thans bestaande versichillen in tarieftocpassing en diversiteit ran rijstellingen worden in dat kader afgeschaft. De dacurdoor optredende distorsies binne'n het regime bor inkomsten uir andelen. veroor:aakt door verschillende substantied l'an clkatr af wijkende tarieven vor economisch gelijke of nagenoeg gelijke ophrengsten, alsmede door de voor de nitroeringspraktijk onberredigende jurisprudentice van de Hoge Raad. kunnen slechts door invoering van een vast tarief worden opgelost. Het vorstel impliceert niet alleen een vereenvoudiging. mar beoogt eveneens een verlichting van de schadelijk werkende economische dubbele heffing op nitgedeelde vemuotschapswinsten te realiseren. Voorts versterkt het de werking ran de kapitadmarkt omalat winstinhouding niet langer fiscalal wordt begunstigd. Door aff-wakking van de dubbele druk zal zelffinanciering door winstinhouding zich minder impliciet kumnen voltrekten dan thans veedal nog het geval is.

Een voorstel tol tariefaumpassing lan de inkomste'n wit aandelen kan miterard nie' los worden bezien van het achterliggende stelsel ran vennontschapshelasting. Nederland neemt met zijn stelsel ran vennootschapshelasting. samen mel Luvemburg. een nogal bijzondere positie in binnen Europa. Ons zogennemde Klassieke stelsel ian rennootschapshelasting gatat uit van een volstreks zelfstandige belastingheffing over de winst ran de aandelenvennootschap, onafhankelijk van de raag of de winst wordt ingehouden of aan de andeelhouders uitgeheerd. Op het moment van dividenduitdeling wordt de andeelhouder die onder de inkomstenbelasting valt op zijn beurt an belastingheffing onderworpen zonder dat daarbij rekening wordt gehouden met de eerder bij de remnootschap gehere'n remootschapshelasting. Deze huidige economische dubbele heffing kan oplopen tot 76\%. Zij rormt zodecende cen zware last roor alle a andeelhouders die onder de inkomstenhelasting vallen.

In de ons omringende landen wordt het rerrekeningsstelsel toegepast. Toepassing ran het rerrekeningsstelsel houdt in dat de rennostschapshelasting betreffende de uitgedeelde rennootschapswinst door de andeellowder met het door hem over het bruto dividend verschuldigde inkomstenbelasting verrekend kan worden. Er is derhalive geen dubbele druk. Uit het oogpum ran draagkracht heeft het verrekeningsstelsel daarom de voorkeur boven het klassieke stelsel. De dubbele heffing ingerolge het klassieke stelsel leidt miet alleen tot discriminatie lan de eigen-rermogensverschatfer, mate legt ook e'n relatief te hoge dubbele druk op anded ellouders met ecen relatief lag inkomen. Dit was ook roor de Eurropese Commissie destijds reden om to kiezen wor een gedeeltelijk rerrekeningssysteen. waardoor de economische dubbele heffing op witgedeelde winsten in belangrijke mate wordt gemitigeerd. Andere in het verleden ter beperking ran deze dubbele druk angedragen compromisoplossingen waren de invoering van e'n gesplitst tarief woor ingehouden en witgedeelde winst en de aftrek van primair dividend.

In international verhand geplaatst heefi de stelselkeuze trounens e'en bijzondere dimensie. De atbakening van de heffingsheroegdheid Inssen het bronland en het woonland rormt een belangrijh politiek probleem. Een geharmoniseerde stelselkeuze voor de vennootschapshelasting geldend roor de gehele EU zal nat mag worden verwacht - zo deze al ooit wordt gerealiseerd - e'venwel nog vele jaren op zich late'n wadhen. In de mussentipd kan het Nederlandse beleid bij toepassing van mijn voorstel gericht blijven op handharing van het klassicke stelsel ran remootschapshelasting. waarbij de andeelhouders ter mitigering van de economische dubbele heffing voor her nitgekeerde dividend in hun woonland worden belast tegen een gematigd arief.

De overstap natre en andytische bohandeling van de inkomsten ait andelen tegen a'n rast en relatief laag tarief zoals in mijn her:-ieningsioorstel wordt bepleit, betekent in dat geval niet alleen e'en vereenroudiging, mat is ook dienstbaar an de gewenste beperking van de economische dubbele heffing. In combinatie met de remootschapsbelasting wordt gestreefil natu een globale druk ran rum 50\%, verdeeld oner de vennootschapsbelasting en de inkomstenbelasting. De precieze invulling van de tarieven ar he ik een aungelegenheid ran de beleidsma- 
kers. Ik beperk mij tot de weergave ran een tabel watrin de diverse combinatiemogelijkheden zim opgenomen met de bibehorende gecombineerde belastingdruk. Slechts ter toelichting vem mijn roorstel heb ik gekozen voor de 38/20-optie die leidt tot een gecombineerde druk ran $50.7 \%$.

Tabel: (jecombineerde IB/Vpb druk

\begin{tabular}{lllll}
\hline IB-laricf: & $20 \%$ & 25 & $30 \%$ \\
\hline Iph-tarief: & & & & \\
$40 \%$ & $52 \%$ & $5.5 \%$ & $58 \%$ \\
$38 \%$ & $50.4 \%$ & $5.3 .5 \%$ & $56.6 \%$ \\
$3.5 \%$ & $48 \%$ & $51.25 \%$ & $54.5 \%$ \\
\hline
\end{tabular}

Invoering ran een relatief lasg uniform tarief roor de inkomsten uit aandelen mag aiteraard niet het gewenste 'globale eremwie hi' in fisscale behandeling tussen de geldstroment verstoren. Bij fiscale regelgeving dient men zich bewast te zijn ran het feit dat doen het tussemvegen ran een BV als transformator winsten. inkomste'n wit arbeid, rente-ophrengsten. beleggingsrendemenren van omroerende zaken fiscalrechelijk gemakkelijk kumnen worden getransformeerd in dividenden. Zou de belastingheffing op dividend door een te lage tariefstelling worden gefacilie'erd. dan zon e'en rum op) de ransformator-BI' ontstatan. De beoogde beleidsdoelstelling om te komen tor een herstructurering ran het haidige regime voor inkomsten uit aundelen zon dan door dergelijke ophrengst-eroderende nitwijkmanoenres budgettair vastlopen. Om dat te vermiiden zijn wee heleidsopries beschikbart. De cerste optic is het huidige toptarief van de inkomstenbelasting re verlagen van oo\% naur $55 \%$. Het drukverschil is dan zodanig afge-wakt dat de doorstroomfondsen natar mijn mening nog nanwelijks levensiathaurheid zullen hebhen. De weede optie is het 38/20\%-regime ant te passen door daarvoor e'en $38 / 25 \%$-optic in de platats te stellen. Dam stijgt de gecombineerde lastendruk tot $53.5 \%$. neardoor de gesignaleerde rariefspanming beduidend is rerkleind. Viteratard zijn roorts combinatic's ran beide anupassingen mogelijk.

\section{Subjectivering van de aanmerkelijk-belangheffing}

Voor de vormgering ran de anmerkelijkbelangregeling is essenticel hoe de atmmerke- lijk-belanghouder moet worden getypeed: als ecen ondernemer of als een aanderlhonder.

Materied kan hot lo0\%-aandelenhesit in e'en BV hetzelfde karakter hebben als het bezit ran een eigen onderneming. Juridisch is de anmmerkelijk-belanghouder e'renwel e'en aumderlhouder. De wetgerer heeft wor de rormgering lan het anmmerkelijk-helangregime de juridische knalificatice doorslaggerend geacht en deze voor de uitwerking van de anmerkelijk-belangregeling als anknopingspum gekozen.

De gronatandechouders verkeren ten op-ichte van acuderlhouders/beleggers edhter in een bij-ondere positic. Zij kumnen immers op doorslaggevende wijer imloed witoefenen op het uirdelingsheleid van de vennootschap. Zodoende ligt het in hum mach de mitdeling van winstreserres ran de andelemennootschap to transformeren in koerswinst op de aundelen en deze te gelegener tijd te realiseren door rerkoop ran de aundelen. Datarom is vor he'n een anmerkelijkbelangheffing in het leven gerocenen. De bij rerkoop gerealiseerde winstreserves worden belast tegen een vast tarief ran 20\%. De aanmerkelijk-belangregeling geldt als het ware als een soort 'tussemergime' voor dic belastingplichtigen. wier subjectice belang bij de andelenrennootschap zowel kenmerken ran ondernemen als ran beleggen rertoont. De atmmerkelijkbolangheffing moet compensatic bieden roor een e'ventueel anti-fiscoul oppottingsgedrag.

Het netlelijke anmerkelijk-belangregime is daurvor echer miet adequat uitge'werkt. De rormgering van het heffingsobject is ten omrechwe gehaseced op het objectiene-bronregime. De anmerkelijk-belanghouder word primair als aunderlhouder ge'-ien e'n de aummerkelijkbelanghoffing wordh beschound als e'en voor schotheffing op de inkomsten nit vermogen. Om die reden is in de geldende annmerkelijk-belangregeling de collectieve benadering ran de inkomsten uit andelen overgenomen. Dit is gebeurd door de verkrigingsprijs en orerdrachtsprijs v'an de aummerkelijk-belangandelenten minste te stellen op het ge'mickdeld op de desbetreffende andelen gestorte kapitan. Deze regel statat bekend als de minimumnatarderingsregel. Door toepassing ran deze regel wordt een koppeling gelegd met het kapitalbegrip ran de broninkomsten uit rermogen. Datardoor zullen de 
ongevenste effecten ran de eerder genoemde opponip-en agio-constructies ook doorwerken naar de aummerkelijk-belangheffing en daar door ophoging wan het gemiddeld gestort kapitaal de claim ran de fiscus op de anmmerkelijkbelangwinst withollen.

Het is begrijpelijk dat door houders van aammerkelijk-belangpakketten op grote schaal ran de gebrekkigheid ran dit systeem is geprofiteerd. Bij belangeloze beoordeling lan dit systeem kan men zich slechts afiragen hoe het mogelijk is dat de wetgever zo lang zo'n rolstrekt krakkemikkig systeem in stand heeft willen houden. Mijn roorstel is daraan thans om redenen van rechtraardigheid een einde te maken. Dit is gemakkelikk mogelijk door binnen de aammerkelijk-belangheffing de mininummuarderingsregel af te schaffen. Dit betekent dat de feitelijk door de belastingplichtige gerealiseerde vermogensmutatie ook daadwerkelijk in de belastingheffing word betrokken.

\section{Uitbreiding van de reikwijdte van het aanmerkelijk-belangregime}

Volgens het geldende aanmerkelijk-belangregime is een aanmerkelijk belang annwezig ten aanzien van de belastinglichtige die onniddellijk of middellijk deelgerechtigd is in het nominaal gestorte aandelenkapitaal ran de - bimnenlandse of huitenlandse - vennootschap, voor meer dan $7 \%$ alleen of te zamen met zijn echtgenoot. en terens roor ten minste een derde gedeelte alleen of te zamen met zijn echtgenoot en de in de wet genoende bloed-en aan'erwanten.

Mijn heraieningsworstel vorziet in een drastische vereenvondiging van dit criterium. Van een aammerkelijk belang is in het her:ieningsvoorstel slechts sprake indien de belastingplichtige al dan niet samen met zijn echtgenoot of ongehuwde partner en zijn bloedverwanten in de rechte lijn ((groot)ouders, (klein)kinderen) ten minste $10 \%$ bezit van het nominaal geplaatste kapitaal. Dit nieawe criterium bevat ten opzichte lan het thans geldende e'n drietal wijzigingen: ten eerste wordt het percentage alangepast. ton theede word de relevante familiegroep drastisch beperkt en ten derde wordt het nominaal geplatiste kapitaal als referentiegrootheid gekozen.
De tweede wijziging betreft het beperken wan de relevante familiegroep. Daardoor zal een groot aantal compleviteiten door wisselende familierelaties tot het rerleden gaan behoren. hetgeen een belangrijke bijdrage levert aan de vereenroudiging ran de regeling. Door het elimineren van de aamveruanten en van de bloedvernanten in de tweede graad ran de zijlijn word een neer overzicholijke grocp gecrë̈erd.

De derde a ampassing hetreft de rerranging ran het nominale gestorte kapitaal door de nieun'e referentiegrootheid 'nominaal geplatste kapitaal. Het nominaal geplaatste kapitaal is een betere maatstaf dan het daadwerkelijk op de aandelen gestorte kapitalal, aangezien het nominale geplaatste kapitaal de stemverhoudingen bepaalt en aan duidelijke vormworschriften is gebonden.

\section{Aanpassing van het heffingsobject}

De aanmerkelijk-belanguinst nordt rolgens de thans geldende wettelijke regeling gesteld op het verschil tussen de overdrachtsprijs en de rerkrijgingsprijs. Aan-en verkoopkosten verminderen het belaste voordeel. Onder rerkrijgingsprijs wordt verstaan de historische verkrijgingsprijs. De verkrijgingsprijs en overdrachtsprijs worden, zoals gezegd. ten minste gesteld op het gemiddeld op de desbetreffende aandelen gestorte kapitaal.

In mijn herzieningsvoorstel zal het heffingsobject op een aantal essentiele punten wijziging ondergaan. De meest belangwekkende aanpassing is het laten vervallen ran de minimumuardermigsregel. Dit betekent dat de feitelijk door de belastingplichtige gerealiseerde vermogensnutatie in de belastingheffing wordt betrokken. Voorts is niet langer bepalend de historische verkrijgings-en remreendingsprijs, maar wordt aansluiting gezocht bij de waarde in het economische verkeer op het moment warrop de belastingplichtige gaat woldoen aan de aanmerkelijk-belangkwalificatic. In vele gevallen zal die warde tevens de historische verkrijgingsprijs zijn, maar dit is niet noodzakelijkerwijze het geval (bijworbeeld bij immigratie).

Dezelfde benadering wordt gekozen bij de verreemdingsprijs. Bepalend is de wate in het 
economische verkeer van de aandelen op het moment w'aarop het aandelenpakket niet langer voldoet aan het aanmerkelijk-belangcriterium. Zodra dat het geval is moet in mijn voorstel in beginsel worden afgerekend. Wel wordt de mogelijkheid geboden de afiekening uit te stellen door te opteren voor de regeling van het fictief aanmerkelijk-belanghouderschap. Dit betekent dat de huidige regeling voor het aflopend aanmerkelijk belang wordt afgeschaft. Ook houdt dit in dat de aanmerkelijk-belangclaim niet, zoals in de huidige regeling het geval is, door tijdsverloop geruisloos verdwijnt.

\section{Conclusie}

Het herzieningsvoorstel impliceert een verbetering van het fiscale inkomensbegrip en een belangrijke tariefvereenvoudiging die de thans werkzame spanningen in de heffingsstructuur oplost. De analytische vormgeving doet geen afbreuk aan de aan de inkomstenbelasting ten grondslag liggende draagkrachtgedachte. Integendeel, omdat de winst uit aanmerkelijk belang evenwichtiger is uitgewerkt, voldoet het nicuw'e inkomenshegrip heter als maatstaf van draagkracht dan in de thans geldende regeling het geval is. Mijn herzieningsvoorstel verlaagt de populariteitsgraad van de rentegroeifondsen ten opzichte van aandelenbezit en dat betekent een versterking van de rechtvaardigheidsdimensie van de heffing. 